\title{
THE GIFTED CHILD: A CONCEPTUAL ENQUIRY
}

\author{
Ruth Cigman
}

\section{INTRODUCTION}

The concept of giftedness has been much debated in recent years. Some use the term 'gifted' as a kind of synonym for 'genius', referring to a phenomenon that is relatively rare. Others use it more liberally, finding gifted individuals in substantial numbers throughout the population. An initial difficulty, then, is the concept's range of application; this difficulty is indicated by the title of philosopher Ruth Jonathan's article: 'The notion of giftedness - or, "how long is a piece of string?"”. A second difficulty is emotional and/or political. Many feel, with P. O. Rogne, that the term 'gifted' implies "receiving something for nothing, and it is difficult to garner sympathy for someone so apparently blessed" (quoted by George, 1997, p. 3). Even if gifted individuals are a) reliably identifiable and b) needy as well as blessed, justice seems to demand that scarce resources go to the less fortunately endowed. A third difficulty is cultural. It is said that the term 'gifted' is applied to individuals who perform highly in socially valued ways. This is reflected in the Western bias towards academic achievement, and neglect of survival-skills like hunting for food. In this respect the concept of giftedness is seen to be arbitrary, an expression of parochial values. A fourth difficulty attaches to a worrying social phenomenon: that of parents who are narcissistically invested in the success of their children. A child may present as gifted, i.e. as a very high achiever, though she is not 'naturally' this way at all. She is no more than a product of pushy parenting, having been trained to perform in certain ways. Such children are sometimes called trophy-children ${ }^{1}$, and we are generally concerned about their fate.

One response to these concerns is to sharpen the definition of giftedness, and many attempts have been made to do this. However little is achieved if, as is typical, the definition

\footnotetext{
${ }^{1}$ See www.wordspy.com/words, where 'trophy child' is defined by Paul McFedries (2002): "A child used to impress other people and enhance the status of the parent or parents."
} 
is disjunctive and unresponsive to common concerns. The well-known Marland Report (1972), for example, offers six criteria for giftedness ('general intellectual ability, specific academic aptitude, creative or productive thinking, leadership ability, visual or performing arts, psychomotor ability'), without explaining why they should be grouped together or indeed why we need a concept of this kind at all. One is left with the impression, as John White says (1970), that giftedness is a "purely artificially constructed concept".

In this paper I shall address some of the scepticism surrounding the concept of giftedness, and outline what I see as a viable concept. If successful, this concept will help us to identify children as 'gifted', not in a way that is cut-and-dried, but in a way that is useful. It will also, hopefully, advance the question of whether gifted individuals should receive special educational provision. It is beyond the scope of this paper to explore the matter of provision in detail, but it seems reasonable to expect that a concept of giftedness should have a bearing on this issue. This is especially the case insofar as the focus of interest is, as here, children rather than adults. The point is not merely to classify individuals; it is to address the question which is implicit in the sceptical position: why bother? It matters little whether you and I disagree about whether Clinton was a gifted politician, but our disagreement about whether a particular child is gifted may affect the school she goes to, the after-school club she attends, the mentor she may or may not have. Our concern about giftedness in children is inseparable from our concern about them as developing individuals.

All this raises the question of potential. It is fashionable when discussing giftedness (by contrast with I.Q.) to point out that one is concerned with potential as well as actual ability. The Marland report, for example, discusses not only "demonstrated achievement" in any of the six areas but also "potential ability" in any of these. Of course most adults are capable of learning, and many have not realised their potential, but the issue of potential is more acute with children than with adults given the rapid development that typically takes place during childhood. The concern about giftedness is largely a concern about missing this window of opportunity, and there can be little doubt that the opportunity is often missed 
through ignorance or neglect of children's potentials ${ }^{2}$. My defence of a concept of giftedness in this paper is motivated by a desire to set this matter straight.

\section{THE CONCEPT OF NATURAL ABILITY}

Gifted children go by many names. They are the highly or exceptionally able, the genius children, the super-bright. So long as the terms of the discussion are clear, it hardly matters which terms we use. Giftedness will do as well as any other.

My aim is to clarify an ordinary, serviceable concept of giftedness that accords with the non-sceptical intuitions of people who raise and work with children. Ruth Jonathan (1988, p. 117) is surely right when she says: 'The common-sense observation that some individuals seem "brighter" than others is basic to an interest in giftedness.' This, I believe, is a good place to start. A gifted child is more than usually bright, at least in some area or other. Sometimes the area of brightness is specific: the child is exceptionally good at maths, say, but little else. Sometimes she is bright 'across the board'.

If this is correct, we have already strayed some distance from the National Academy for Gifted and Talented Youth (2002, p. 5) definition, which identifies gifted children in a two-tiered way ${ }^{3}$ as "the top $1 \%$ or the top $5 \%$ of pupils... in terms of their academic ability". ${ }^{4}$ Quantitative definitions of giftedness are currently favoured by the UK government, though it

\footnotetext{
${ }^{2}$ On this point Israel Scheffler writes (1986, p. 203): "The capacity to learn is not an unlimited resource which can be lightly squandered."

${ }^{3}$ While it can be useful sometimes to distinguish between 'gifted' and 'exceptionally gifted', I believe that the alleged statistical basis is misleading. These issues are discussed later in the paper.

${ }^{4}$ This definition is linked to a distinction between giftedness and talent which I shall not follow. According to this definition, gifted students have high academic ability, whereas talented students have ability in "creative arts or sports". This definition does not accord with ordinary usage, for we normally call exceptional young violinists (for example) gifted and talented interchangeably. It is true that 'talent' tends to have a creative implication (a 'talented child' is likely to be musical, artistic etc.), but the idea that academic excellence is non-creative is misleading.
} 
is far from clear how potential as opposed to actual ability is to be measured. At the very least there seems to be substantial scope for error, and since differentiated provision is at stake, also scope for injustice. The problem with quantitative definitions is that the size of the target group is determined in advance. One says: in this class I shall pick out two (or whatever $5 \%$ of the class number is) children as 'gifted': no more, no less. This idea corrupts what I am calling the ordinary, serviceable concept, which views giftedness as a kind of property of children in relatively non-comparative ways ${ }^{5}$. Of course it may be said: we only have enough resources to give enriched or accelerated educational support to two children in every forty. But this assumes that enriched or accelerated educational support will be beneficial for two children in every forty. This is a large assumption.

Jonathan's common-sense observation that some individuals seem 'brighter' than others leads in a different, and I believe more promising, direction. The concept of brightness, and particularly the concept of unusual or super-brightness, has an underpinning that is both problematic and, I would suggest, undeniable. This is the idea of naturalness or innateness. To say that one person is much brighter than another implies (in a way that is hard to pin down but also hard to deny) that they were born, or are naturally, that way. This is problematic because it recalls the erroneous idea that intelligence (I.Q.) is an innate, measurable property of individuals that is immune to environmental influence. It has been amply pointed out that this idea is nonsensical because there is no way of extrapolating from the environmental influence to isolate (or indeed measure) a purely genetic endowment. From the fact that one cannot do this it does not follow, however, that one can never detect a genetic or innate influence. The following, by a well-known sceptic in this area, is surely true:

There is no denying that from an early age young people do differ in their patterns of ability. One child does well at arithmetic but appears incapable of learning to play a musical instrument. Another youngster is hopeless at both music and arithmetic but has a flair for new languages. Even within the same family there may be striking differences between siblings: one daughter takes to the task of

\footnotetext{
${ }^{5}$ There $i s$ a comparative dimension to the concept of giftedness, but my point is that this is poorly served by statistics. This issue is discussed more fully in Section Four.
} 
learning to play the piano with apparent ease, while her older sister struggles to master a few elementary pieces.

In this passage Michael Howe (1999, pp. 189 - 90) seems to acknowledge what I am calling natural brightness. In everyday life we use terms like 'flair' and 'strength' to refer to this in particular areas of learning, and it is a small step from here to the recognition that some people have many strengths, or remarkable strengths, and are therefore super-bright, or gifted. To the radical sceptic who claims that there must be an environmental explanation for such differences, we can only say that this appears to be contradicted by the facts.

One of the main sources of unease about the concept of giftedness is expressed in my fourth objection above: the 'pushy parent' objection. This says that the 'label' of giftedness is likely to reinforce parental delusions, for natural and parentally-contrived giftedness are indistinguishable. This is wholly false. Natural and parentally-contrived giftedness are indeed distinguishable, but only given a frank acknowledgement of the concept of natural brightness. They are distinguishable as any other empirical differences are distinguishable; by careful observation of the facts of the case, particularly the ways in which parents do or do not exercise an influence over their children.

The point of saying that some children are naturally brighter than other children is not, as some fear, to give the brighter ones accolades or to reinforce unhealthy divisions. It is to identify and respond to children's potentials appropriately, particularly when these are masked by social inequalities. A naturally bright child may be passed over as such because her performance is unexceptional. Her performance may be unexceptional because she was never read bed-time stories and didn't hold a crayon until she was five. This child may benefit from being identified as unusually bright (using criteria to be discussed in Section Four); this will enable her teachers to address the gap between her actual and potential performance. She must be distinguished from the child whose performance is, let us say, exceptional simply because she has been intensely pressured and coached. The latter is vulnerable to various sorts of unhappiness insofar as she is viewed as unusually bright, 
whereas the former may be vulnerable to unhappiness insofar as she is not seen this way. It is because this difference is so important that we need to accept, with Ruth Jonathan, that observations about (natural) brightness are "basic to interest in giftedness".

Natural ability and environment are of course deeply intertwined. Since learning begins at birth there is little prospect of quantitatively disentangling these at a later date. What is being suggested here however is that there are occasions on which natural and environmental influences can and should be evaluated (as distinct from measured) independently. We may observe that a child has natural ability that is neglected or dormant because her environment is non-propitious; or that a child who has little natural ability performs extremely well, having been under great pressure to succeed. This difference points towards the following fourfold distinction:

1) the child who is very bright, and benefits from propitious environment;

2) the child who is very bright, but lacks a propitious environment;

3) the trophy-child, who achieves highly as a result of a pressured environment, but who seems 'not bright' or only 'moderately bright', and strained or alienated by the experience;

4) the child who seems 'not bright', and lacks a propitious environment.

I am not suggesting that all children fall into one of these groups. Both brightness and propitious environments are less than black-and-white affairs, and a great many children undoubtedly belong to more than one group, or shift between groups. The groups are conceptual, primarily: they mark out distinctions which I am arguing educators must be free to use.

Without these distinctions we are not free to raise the questions:

- Is this child seriously under-achieving? Is a non-propitious environment masking the child's considerable natural ability? 
- Is this child seriously over-achieving? Does her success in exams mask a manipulative adult who is pushing the child inappropriately?

It is important that educators are able to raise these questions, and generally try to understand interactions between children's natural abilities and the environments in which they find themselves. We sometimes need to ask, to put it crudely, what children are made of, if we are to understand their struggles and help them. The failure to do this, indeed the resistance to doing this, can be detrimental to children generally, and to gifted children in particular.

\section{GIFTEDNESS AS AN EDUCATIONAL DIFFERENCE}

Though the literature on the concept of giftedness is large, there is next to nothing of a balanced or analytical nature on this topic. Gifted children, so-called, have their advocates and their detractors. The advocates call for recognition and provision; the detractors express a range of responses, from a downright sneer ("the mummies and daddies think the little sprot is a genius" (T.E.S. website 2002)) to a more reasoned scepticism and egalitarianism. On both sides, there appears to be a prior commitment: to addressing the alleged needs of particular children, on the one hand, and to a fair and rational concept of educational difference, on the other. Both commitments, moreover, seem well supported by arguments. Some children, say the advocates, need a kind of provision that a homogeneous educational system cannot provide. They need this not because they are struggling to learn, but because they learn too easily, too quickly or too well. The detractors point out that such children have an advantage, and that they do not form a clearly identifiable group. It should be possible, they say, to relieve debilitating boredom in a homogeneous system by providing special challenges for unusually bright children. All children are different and should be treated as individuals. Rather than siphon off the so-called gifted into special institutions, the right response is to address ability-differences as effectively as possible. 
The result is a stand-off, the educational context of which is well-described by Alan Dyson (2001, p. 25) in this passage:

[There is] a fundamental contradiction within the education systems in the UK and the USA (and, we might guess, elsewhere in the liberal democracies) between an intention to treat all learners as essentially the same and an equal and opposite intention to treat them as different. All learners are the same in their essential human characteristics, in the rights and entitlements which are ascribed to them and in their participation within some more-or-less loosely defined process of education. At a practical level, therefore, we seek to educate them within common schools, through a common curriculum and by means of broadly common pedagogical strategies. All learners are different, however, insofar as they are individuals with distinctive learning styles, needs and interests. We seek to respond to these differences by placing them in different teaching groups, offering them variations on the common curriculum, developing individual teaching programmes and so on.

Working within this contradiction creates a series of dilemmas for education professionals and policy-makers. Put simply, the more their educational responses emphasise what learners have in common, the more they tend to overlook what separates them, and the more they emphasise what separates and distinguishes each individual learner, the more they tend to overlook what learners have in common.

We need to explore this contradiction and its attendant policy difficulties. Something is seriously amiss if we cannot keep a conceptual handle on both commonness and difference. It is my view that giftedness detraction, accepted by many as a politically correct stance, reflects precisely this difficulty. The difference between bright and not-so-bright children slots unobtrusively into the concept of mixed ability teaching. Problems set in with children who appear so bright that the questions arise: is this child uneducable within a mixed ability context? Is she so different from other children that it is wildly unrealistic to expect her to 
benefit from a mixed ability environment? These questions worry at the concept of educational difference, and with them come some serious difficulties.

In the paper referred to earlier, Ruth Jonathan (1989) argues that giftedness is not an educationally useful difference. This is not to say, she writes, that "there are no differences in capacity or attributes between children, nor am I suggesting that a homogeneous education should ignore such differences" (pp. 123 - 4). Rather:

I am simply denying that there are two groups of children - 'the gifted' and (by implication) the non-gifted mass of the population. There is no separate group which we can categorise even in principle, in order to specially cater for their individual differences. Such differences do indeed exist, but not between two groups of children, rather amongst all children. This implies not two programmes of educational provision, but one general programme sensitively adjusted to the individual differences of each child.

What is Jonathan saying in this passage? A general point to consider is that the concepts of sameness (or similarity) and difference rest on a further concept of a respect (or several respects) in which two or more items (people, things, situations, ideas) are compared. Two items may be similar in one respect and different in another; whether we call them similar or different depends on our interests and purposes. If the concept of giftedness is to be useful educationally, we need to identify a respect (or several respects) in which gifted children are usefully seen as a 'separate group', i.e. as similar to each other and different from other children.

The ordinary, serviceable concept of giftedness should reliably pick out some children sometimes, and there needs to be a point in its doing so. To this extent, there must be a 'separate group', a group that we can 'categorise in principle'. Let's consider two relatively straightforward examples: Ruth Lawrence and Gary Kasparov at, say, age twelve. It would be hard to grasp the motive of someone who wanted to withhold the description 'gifted' from such children, given their remarkable and apparently natural aptitudes for 
mathematics and chess respectively. If, however, someone was sceptical, one might point to an obvious respect in which these children are reasonably 'grouped' together, and distinguished from most other children. Neither was easily accommodated at school - at least when it came to maths and chess. Lawrence would have been wasting her time in the KS3 maths lessons, and Kasparov would have been wasting his time in the school chess club. At least this is presumably the case unless special provision was made.

So something along the lines of 'not fitting in well with most same age children (at least in certain subject areas), because of unusual mastery or ease of learning' might be the beginnings of a respect in which gifted children are different from other children and similar to each other. There are several ways in which this suggestion might be rebutted. First it might be said that if gifted children (so-called) don't fit in with other children, all the more reason for ignoring their gifts (so-called), and encouraging them to see themselves as ordinary. (Something like this thought underlies the disparaging notion of the 'hothouse'.) Second, it might be said (as Jonathan says) that we need to recognise all individual differences, and provide sensitively for these. Third, it might be said that the Lawrences and Kasparovs are vanishingly rare, and irrelevant when it comes to public policy. It might be conceded that they are different, and the question raised, so what? Problems set in when every Tom, Dick and Harry is described (as often as not by his parents) as gifted, on the strength (at best) of what is more accurately described as brightness.

I shall consider these objections in turn.

1) Children should be encouraged to see themselves as ordinary. This suggestion springs from what Dyson calls the educational response that emphasises "what learners have in common". It may be perfectly reasonable as rule-of-thumb, and indeed if a child is being beguiled by her parents into believing that she is superior to other children, this injunction will be appropriate. It does not follow from this that it is always appropriate. On the contrary the injunction may be used to put pressure on a child to conform - a kind of psychological denial - in which case it may be positively harmful. 
2) We need to recognise all individual differences. In other words, what all learners have in common is that they are different. In a sense this cannot be denied, but it is a fairly vacuous statement, and the problem with Ruth Jonathan's idea of one programme "sensitively adjusted to the individual differences of each child" is that it sounds idealistic and impractical.

3) The category of gifted children is either vanishingly small or hopelessly ragged. This, as I see it, is the key objection. If there were typically a couple of Lawrences or Kasparovs in every classroom, the suggestion that they should be encouraged to blend in or that they are only different in a sense that applies to all, would sound rather lame. If, alternatively, there were typically no Lawrences or Kasparovs in a classroom, but some children who resembled them in some educationally significant respect, we might also dismiss these suggestions. I believe that the latter may be the case. Gifted children may be rare but not vanishingly so, and reasonably seen to constitute a 'group' even though not all members of the group are paradigmatic cases.

Objection 3) needs to be answered; we need to identify our target group. This is the challenge I now want to address.

\section{WHO IS GIFTED?}

Dyson identifies two opposing educational tendencies. One emphasises "what learners have in common", and the other emphasises "what separates and distinguishes each individual learner". As implied by the term 'emphasis', one tends to predominate over the other. But both are important, so what should we do?

It will be useful to explore Ruth Jonathan's argument further in order to get to grips with this problem. Her emphasis is on commonality, and her idea of sensitively adjusting to the individual needs of each child sounds a bit like an afterthought. The emphasis on commonality is betrayed at several points, but most clearly when she reveals that she is exploring "stumbling blocks" or "obstacles" to what she calls a "valid understanding of which 
individuals possess the inherent capacity which is likely to lead to future high achievement." Though not spelt out as such, the structure of her argument goes something like this:

1) Ethically and politically, all children should be seen as 'the same'. They should have equal entitlements and so on.

2) The idea of giftedness implies that some children are entitled to a better or more stimulating education than others.

3) 1) is a cherished ideal. Therefore we should presume that 2) is wrong unless we discover solid grounds for distinguishing and giving preferential treatment to socalled gifted children.

4) An example of a solid ground would be evidence of an inherent capacity possessed by some, but not all, which is likely to lead to future high achievement.

5) There are many "stumbling blocks" and "obstacles" (logical and empirical) in the way of providing such evidence.

6) Therefore 2) is wrong.

There are numerous flaws in this argument, and I shall not try to disentangle them here. In particular the move from 3) to 4) is flawed, because it imports assumptions about the notion of a 'solid ground'. Jonathan is reacting strongly in her paper against psychometric conceptions of intelligence, as well as against the idea that precocity is a reliable indicator of future high achievement. This is sound, but the emphasis on equality and commonality squeezes out considerations of difference. Claim 2) is doomed from the start; it is as though gifted children (so-called) are guilty unless proved innocent, i.e. a spurious group unless their separate existence can be established. The tools by which this might be achieved are precisely those which Jonathan rejects. For gifted children to earn the status of a 'separate group' educationally, they would have to demonstrate their existence psychometrically, and also demonstrate plausible connections between their psychometric (current) identities and future high achievement. By these exacting standards, it is no wonder that they fail. 
The reason why there seems to be so little common ground between advocates and detractors is that the questions one asks depend heavily on one's initial emphasis. Ruth Jonathan the detractor asks: which individuals possess inherent capacities that are likely to lead to future high achievements? This is a national interest question, and it is not an unreasonable one, except that the answer is almost certainly: we don't know. This fairly predictable answer means that the question can be raised without endangering our familiar egalitarian concerns. We do not know who the future high achievers are likely to be, so we had better treat children as the same. I have nothing but respect for the egalitarian concern, but there is another question that needs to be asked, that many teachers and parents do ask, and this is not a national interest question at all. It is what one might call an individual need question, and it asks: what should we do about those individuals who do not fit in well with their peers educationally for reasons that seem linked to their unusual brightness? This sort of question is often dismissed on the grounds that the educational needs of such children are doubtless exaggerated. But this is too easy. Without empirical evidence, we cannot know that they are not needy.

Jonathan neglects an important possibility: that a legitimate concept of giftedness would be associated with the needs and entitlements of individuals. It seems obvious enough that Ruth Lawrence's needs would have been neglected if she had been stuck with mathematics at Key Stage 3. Not only this: her entitlement to an education in mathematics would have been neglected. The concept of entitlement is more straightforward than the concept of need. The entitlement to education is clearly not fulfilled by trying to teach a child something she mastered some years ago. Whether children need to be properly educated is another matter, but it seems reasonable to suppose that the boredom and frustration characteristic of many gifted children are evidence of need.

The challenge, we recall, is to discover respects in which giftedness is usefully seen as a 'difference'. We need criteria, in other words, for the application of this concept, and these must address at least some of the concerns that were discussed in the introduction. The 
concept of giftedness must be neither too broad nor too narrow: the 'group' of gifted children should not be raggedly large or vanishingly small. Giftedness must not be statistically related to performance, as per the government of this country. I have made several further suggestions. I discussed the young Lawrence and Kasparov, two exceptionally high achievers, and suggested that such children are paradigmatic. I also suggested that 'not fitting in well educationally with most same age children by virtue of unusual mastery or ease of learning' was a step in the right direction. I suggested, finally, that an understanding of giftedness might be expected to issue from the emphasis on difference, rather than the emphasis on similarity. The emphasis on difference would highlight the non-fulfilment of certain children's needs and entitlements.

Against this background I now want to propose some criteria for giftedness. The first and primary criterion is exceptionally high achievement in at least one significant area of learning. (I shall presently discuss the cultural objection, mentioned earlier on, to the concept of an 'area of learning'.) Exceptionally high achievers do not typically fit in well with same age children in terms of their educational needs and entitlements. For example a common though not invariable corollary of exceptionally high achievement is an exceptional desire to achieve. This can give rise to needs: gifted children are often obsessional about acquiring knowledge and/or skills in a particular area. Further, exceptionally high achievers tend to exhibit mastery in areas where others are struggling, and we have seen that this can conflict with their entitlement to learn.

However the concept of exceptionality is not straightforward, and its susceptibility to different interpretations lies behind the charge of 'raggedness'. A child who is exceptional in one context may be unexceptional in another, where the standards are generally higher. We also have the concept of being exceptional 'by any standards': the young Lawrence and Kasparov clearly fell into this group. What this indicates is a need to distinguish relative from absolute giftedness. (The government distinction between top 5\% giftedness and top 1\% giftedness is surely a misguided way of trying to do this). The relative sense is 'weaker' than 
the absolute sense, but this does not mean that it is not useful, given that the point (as I am arguing) of using the concept in the first place is to address children's needs and entitlements. Like Marge Simpson's sky blue hair that seems to disappear on cloudless days, giftedness may 'dissolve', i.e. cease to be an issue, when a child moves to a school that is more suited to her abilities. Far from invalidating the concept, this situation should be applauded since it means that the child's needs and entitlements are now being met.

Jonathan's sub-title 'how long is a piece of string?' suggests that the concept of giftedness is invalid because it lies on a slippery slope. This is rather like saying that the question 'at what age may a child be reasonably left alone at home?' is meaningless because it lies on a slippery slope. However, this is not so. It is an awkward question, certainly, but its meaningfulness is guaranteed by the fact that it sometimes yields robust answers. Most would agree that a two year old child should not, but a fourteen year old child may, be left alone at home for periods of time. In between is a grey area which we may need to negotiate by reference to individual children. Equally, as I suggested at the outset, some children clearly are gifted, and others clearly are not, whereas for many children in between, it is a matter of judgement and circumstance. Different children become 'foregrounded' as gifted in different schools and communities, and this is as it should be.

A child who habitually performs exceptionally well, either 'by any standards' or by the standards of a particular community, fulfils what I would call the primary criterion of giftedness. Note that this criterion overlaps with what I earlier called the 'beginnings of a respect' in which gifted children should be seen as 'different', i.e. that they do not fit in well with most same age children (at least in certain subject areas), because of unusual mastery or ease of learning. We now see how 'most same age children' can refer to those in a particular community or to same age children generally.

In addition to this primary criterion, I suggest that there are two 'loose' criteria or 'indicators' of giftedness, i.e. indicators of the potential ability to perform exceptionally well. The first is exceptional or remarkable insight, shown in unsystematic ways. For example a 
generally low-achiever betrays, through a remark here or there, an extraordinary capacity to grasp certain concepts or ideas. She has flashes of extraordinary insight, say, though her concentration and output are poor. This sort of profile - occasional brilliance, unsteady concentration or performance - points to a worrying discrepancy between potential and actual ability which could have a social or emotional source. This is the sort of case that rightly arouses the concern about wasted potential that is central to the issue of giftedness.

The second indicator of giftedness is a passion for learning. We have all come across children who are education-junkies, preferring to spend their free time at museums or with their heads in books than playing with their friends. It is not impossible to have a passion for learning without the ability to achieve highly, but there is obviously a strong psychological connection between these. As Christopher Winch (1990, p. 37) writes:

Excellence... will thrive on a strong degree of interest and commitment. Interest in an activity will lead to more practice, more knowledge, and greater understanding. So will a strong desire to do well.

Even if the education-junkie is not getting the highest grades, teachers should be on 'giftedness alert' for this individual. They should be on the look-out, that is, for boredom, rapid learning and high (if erratic) achievement, as well as for possible counter-indications, like a parent that the child is eager to please by this kind of behaviour. In the absence of the latter, it seems to me that lovers of learning should generally be grouped with gifted children in the primary, performative sense, whether or not they too are achieving exceptionally highly. To do so may mean giving them opportunities to do precisely what they (and we as educators) want them do to, namely devote themselves wholeheartedly to learning ${ }^{6}$.

The concept of giftedness, I suggest, belongs to the area I have outlined. The primary criterion for giftedness is absolute and relative exceptionally high achievement, but giftedness

\footnotetext{
${ }^{6}$ This is not to deny that the wholehearted devotion to learning can be excessive. It would be wrong, however, to assume that it is excessive without establishing ways in which it is genuinely harmful to the child. My impression is that this assumption is frequently made.
} 
is also indicated in the absence of such achievement, first, by unsystematic, unusual insight, and second, by an unusual passion for learning. As I said earlier on, the primary criterion and an unusual passion for learning often co-exist. People who excel in a certain activity typically (though not invariably) love engaging in it, and are highly motivated to learn. Rawls cites what he calls the Aristotelian Principle, which says that:

other things being equal, human beings enjoy the exercise of their realised capacities (their innate or trained abilities), and this enjoyment increases the more the capacity is realised, or the greater its complexity. ${ }^{7}$

My only reservation about this principle is that it is under-stated. The term 'enjoy' does not capture the single-mindedness with which gifted individuals often pursue their interests. This is important because it is when a desire becomes not merely strong but overwhelming that we are tempted to say that it gives rise to needs. There is a sense in which heroin addicts do not need heroin, but also a sense in which they do, and the realisation of abilities (whether innate or trained, or more likely a combination of the two) may be associated (unlike a need for heroin) with positive, life-enhancing needs.

The passion for learning is an important and neglected aspect of giftedness. This is not to say that all gifted individuals are highly motivated to develop their gifts, but there is a sense in which, as implied by Rawls' Aristotelian Principle, a lack of motivation to develop a rare or remarkable gift is a puzzling, or disturbing, phenomenon. Sometimes it is understandable. There are many people with musical gifts who, for temperamental reasons, cannot bear the drudgery that is required on a daily basis to master a musical instrument. I have never known such a case in which there was not profound regret and ambivalence about the neglect of such a gift, and it seems to me that teachers should do all they can to help children (where help is needed) to take pleasure in their gifts.

Rawls, John (1971), p. 426 
I now want to consider a profile of a fourteen year-old boy who illustrates my point about indicators of giftedness. He seems, I suggest, like a gifted individual, despite being a 'walking disaster' at school:

Martin is considered to be a 'walking disaster' by his teachers. He seems to live in a world of his own. He is never where he should be and is invariably late for classes... His handwriting is appalling, and he is reluctant to put pen to paper. He has a very sharp wit and has become the class clown. He was quite interested in secondary school in the first two years, when he enjoyed the wide range of subjects. Last year things began to go wrong for him. He found teachers to be more concerned with maintaining their authority than with the pursuit of truth. He found the move to set syllabuses very frustrating because there were fewer opportunities for 'theorising' and 'playing' with ideas.

His relationships with teachers are extremely poor, since he tends to challenge and question both their authority and their knowledge. He is also rather dismissive of the views of his peers. His science teachers, however, value his contribution to class discussion, since he shows remarkable insight and understanding, beyond that of most young people of his age. He would like to devote himself exclusively to science, and science-related subjects, and dispense with the rest. He should be capable of achieving good examination results, were his present attitude and ability to present his work to change... One is tempted to ask what Martin gets out of school! $\quad$ (David George, 1992, p. 25):

This is a short profile, but I think that most people would agree that Martin is at least a candidate for giftedness. It seems likely, for example, that he could benefit from a programme for gifted young scientists. How one might balance his claim to be admitted on to such a programme against the claim of a high but unmotivated scientific achiever, I have no idea. What does seem obvious is that the definition of giftedness as the "top $1 \%$ or the top 
$5 \%$ of pupils... in terms of academic ability" does not remotely address this question. If we are serious about responding to children's needs and entitlements, we must set aside statistics and try to balance the claims of individual children.

Martin is a candidate for giftedness because he has enthusiasm and insight in an area that we value socially. Ruth Jonathan articulates the cultural objection when she writes: "What gifts or talents are selected for attention will be relative to the goals and values of the selecting group." Giftedness, it is implied, is an arbitrary concept. We reward gifted scientists and musicians but not gifted hairdressers, skate-boarders or players of computer games. This is discriminatory, unfair.

This objection is common, but I confess I find it perplexing. I earlier dismissed the idea of responding to concerns about giftedness with a definition (the problem is who we pick out as gifted, and for what purposes; towards these ends definitions are often less than useful), but the following definition of giftedness responds frankly to the 'arbitrariness' objection in a way that surely cannot be bettered:

Gifted young children are those who have the capacity to learn at a pace and level of complexity that is significantly advanced of their age peers in any domain or domains that are valued in and promoted by their sociocultural group. ${ }^{8}$

The expression 'capacity to learn' is unhelpful, since many gifted individuals have learning difficulties, but the interest of this definition is its reference to socioculturally valued domains. If one feels uneasy about this, the unease should be directed towards education generally, which is imbued with value judgements because it aims to prepare children for adult life within particular societies. As Christopher Winch writes:

...education is intrinsic to any society, since any society that has ever existed or will ever exist has to prepare the young for adult life. Education is a practice as ancient as the human race. This means that it carries with it an enormous cultural tradition which runs back to the roots of any society. ${ }^{9}$

\footnotetext{
${ }^{8}$ Porter, Louise (1999), p. 33

${ }^{9}$ Winch, Christopher (1996), p. 34
} 
It is against this background that we reward and encourage some gifts rather than others. This is not to deny that elitism and prejudice exist and should be challenged; nor is it to deny that we should acknowledge more ways in which children can be gifted than we tend to at present. It is to say that elitism and prejudice are not, as is often assumed, inevitable corollaries of the concept of giftedness.

\section{CONCLUSION}

I have argued that it is educationally useful to regard gifted children as a 'group'. Contrary to what many detractors say, I suggested that there are criteria by which they can be reasonably identified, and that they are likely to have unmet needs and entitlements for a cluster of reasons, unless special provision is made. For my money, this justifies the concept. To say that gifted children constitute a group is not to say that they have nothing in common with other children; nor is it to say that they are better. It is to say that, with important qualifications, they may and often should be seen as 'different'. That they have the potential for future high achievement is not a point that I have stressed here. Such potential is clearly present, but it is also present in other children: gifted children do not have a monopoly on future achievement. Having said this, it seems obvious that, given their unusual capacities and passions, achievement is often something that gifted children need if they are to lead fulfilling lives. I mean achievement, not for trophies, but for its own sake, and at a relatively high level. This being so, there is clearly a national interest argument in favour of the view I am proposing; but without prior consideration of need and entitlement, the national interest argument flounders on concerns about coercion.

I have said little about the varieties of gifts that individuals may have in this paper. In the spirit of Howard Gardner, many have been quick to point out significant differences between children who are gifted artistically, mathematically, linguistically, musically, 
ethically, physically (at sport), and so on and so forth. I believe that these differences exist within the terrain that I have demarcated. Whether a child is a gifted footballer, chess-player, musician or cartoonist, insofar as we undertake to provide an education in any of these areas, we must undertake to respond to needs and entitlements as discussed here. Chess champions need something other than after-school chess; without this, they are likely to be bored, impatient, frustrated. Mathematical prodigies are entitled to an education in maths, and should not be expected to spend years treading water.

If gifted children constitute a separate 'group', should we put them in separate institutions? The answer is, not necessarily, though the desirability of flexible arrangements is implied by my argument. Just as there are arguments in favour of separate institutions, so there are arguments against. The latter refer to those emotional and social considerations that the giftedness detractors are at pains to point out. All that is implied by my argument is that these considerations are not the whole story: that gifted children as a group are liable to have particular needs and entitlements. From here the question is not: do they need special institutions? It is: how (in special institutions or otherwise) can we meet these needs and entitlements?

That the detractors' argument is seriously imbalanced has been the main thrust of this paper. In the extraordinary penultimate paragraph of her paper, Ruth Jonathan betrays the extent of this imbalance in her argument:

If favourable development results largely from favourable stimulation, and if education is the attempt to provide favourable stimulation in order to produce favourable development, then questions of which individuals this stimulation should be offered to are disguised proposals about which children should be educated.

This is alarming. Jonathan seems to think that raising questions about provision for gifted children threatens provision for other children. The question, as she sees it, is: which individuals should be favourably stimulated? This is the same question (she rightly says) as: which children should be educated? But whoever said that 'which individuals should be 
favourably stimulated?' was the question? The concern around giftedness is that some children may need greater stimulation than is normally provided at their age, but 'greater' is not the same as 'more favourable'. 'Greater' may mean more advanced, more intense, more challenging. If a child is an education-junkie, why should she not receive this, and why should other children be seen to be missing out?

The idea that if gifted children are properly educated, other children will lose out, places a heavy burden on the gifted ones. We need to relieve children of burdens, and responding to their passions for learning as discussed earlier is an important step in this direction. In the light of this conclusion, it seems appropriate to give the last word to psychologist Joan Freeman (2001, p. 193):

The big question which pounded through my head...was why so many of these bright eager children had needed to struggle so hard to even partly realise their gifts. It was not only unfair on them but a wicked waste of everyone's energy... Far too much of their energy went into fighting the establishment, supposedly there to help them, or dissipated into wrong channels because of poor guidance...

\section{$\underline{\text { REFERENCES }}$}

Dyson, Alan (2001), Special needs in the twenty-first century: where we've been and where we're going, British Journal of Special Education, 28, 1, pp. 24 - 29

Freeman, Joan (2001), Gifted Children Grown Up. (London:

David Fulton Press)

George, David (1997), The Challenge of the Able Child (Second edition) (London: David Fulton Press)

Howe, Michael (1999), Genius Explained (Cambridge University Press)

Jonathan, Ruth (1988), The notion of giftedness - or, 'how long is a piece of string?' British Journal of Educational Studies, 26, 2, pp. 111 - 125 
Marland, S. P. (1972), Education of the gifted and talented, Report to the Congress of the United States (Washington D.C.: U.S. Government Printing Office)

McFedries, Paul (2002), www.wordspy.com/words

National Academy for Gifted and Talented Children (2002), Talent Search: guidance for participants

Porter, Louise (1999), Gifted Young Children (Buckingham: Open University Press)

Rawls, John (1971), A Theory of Justice (Belknap Press of Harvard University Press. Cambridge, MA.),

Scheffler, Israel (1986), 'Human nature and potential', in Education, Values and Mind, David E. Cooper ed. (New York: Routledge and Kegan Paul)

White, John (1970), 'The bloafed and the gifted', Times Educational Supplement, November 20th

Winch, Christopher (1990), Language, Ability and Educational Achievement (New York: Routledge) 